assessment of a pelvic tumor and distant spread of the disease. Cervical cancer stages for each patient were modified according to 2018 International Federation of Gynecology and Obstetrics (FIGO) staging for cervical cancer.

Result(s)* A total of 1896 new cervical cancer cases were assessed by our multidisciplinary tumor board in a period of 14 years. Five hundred and eight patients (27\%) were eligible for surgical treatment. Distribution according to stage revealed 62 patients with stage IA2 (12\%), 318 (63\%) IB1, 82(16\%) IB2 and 46 patients (9\%) with stage IIA. Class B radical hysterectomy was performed in 380 patients (75\%), while the rest $128(25 \%)$ underwent a Class C procedure. In all cases, we performed a full bilateral pelvic lymphadenectomy, followed by palpation of para-aortic lymph nodes. We also recorded $90(4.7 \%)$ patients eligible for fertility-sparing treatment, that underwent radical trachelectomy with pelvic lymphadenectomy. The rest 1388 patients were diagnosed with advanced stage disease (IIB-IV) and were referred to definitive concurrent chemoradiation treatment or chemotherapy, followed by radical radiotherapy and brachytherapy.

Conclusion* Designing the optimal treatment for patients diagnosed with cervical cancer demands a multidisciplinary approach, a thorough assessment of the extension of the disease and a detailed consultation for the patient and her family.

\section{THE ANALYSIS OF STATISTICS OF CERVICAL CANCER IN UKRAINE}

L Zrielykh*. Universal Clinic 'Oberig', Center of oncology, Kyiv, Ukraine

\subsection{6/ijgc-2021-ESG0.66}

Introduction/Background* Cervical cancer (CC) takes the fourth place in incidence and mortality rate in women worldwide. In Ukraine cervical cancer occupies the fifth place in the incidence and seventh place in the mortality rate from cancer in female population.

Methodology Analysis of data of Globocan 2020, National cancer registry.

Result(s)* Number of new CC cases in 2015 in Ukraine was 4166, in 2019 - 3936. Number of deaths from CC in 2015 was 1687, in 2019 - 1579 .

Age-standardised incidence rate (world standard) of CC in 2015 was 8,2; in 2019 - 7,6. Age-standardised mortality rate (world standard) in 2015 was 3,1; in 2019 - 2,8.

The relative frequency of cervical cancer incidence in the structure of 10 leading cancer sites in Ukraine in 2015 was $5,9 \%$; in $2019-5,4 \%$ (both $5^{\text {th }}$ place). The relative frequency of CC mortality in the structure of 10 most common cancer sites in Ukraine in 2015 was 5,8\%; in 2019 - 5,9\% (both $7^{\text {th }}$ place).

The relative frequency of cervical cancer incidence in the structure of 5 leading cancer sites in age group 18-29 years in Ukraine in 2015 was $11,8 \%$ ( $3^{\text {rd }}$ place); in $2019-8,1 \%\left(4^{\text {th }}\right.$ place); in age group 30-54 years in 2015 - 13,4\%; in 2019 $12,4 \%$ (both $2^{\text {nd }}$ place).

The relative frequency of cervical cancer mortality in the structure of 5 leading cancer sites in age group 18-29 years in Ukraine in 2015 was 8,4 ; in $2019-13,6 \%$ (both $3^{\text {rd }}$ place); in age group 30-54 years in $2015-14,2 \%$; in $2019-16 \%$ (both $2^{\text {nd }}$ place).

In 2016 patients diagnosed with $4^{\text {th }}$ stage of CC comprised $4,8 \%$, in $2020-9,1 \%$.
Main problems of cervical cancer in Ukraine are the absence of government vaccination programme and lack of women`s adherence for regular screening and treatment.

Conclusion* According to statistical analysis the incidence and mortality rate of CC in 2019 remains at the same level as in the 2015 .

The number of patients with $4^{\text {th }}$ stage has almost doubled in 2020 compared to 2016.

In 2015 CC occupied the $3^{\text {rd }}$ place in the incidence of 5 leading cancer sites in age group 18-29 years, in 2019 this pathology ranks the $4^{\text {th }}$ place, yielding to breast cancer.

\section{OUTCOMES FOLLOWING OPEN RADICAL HYSTERECTOMY AFTER IMPLEMENTATION OF AN ENHANCED RECOVERY AFTER SURGERY (ERAS) PROGRAM}

${ }^{1} \mathrm{~N}$ Agustí ${ }^{*},{ }^{2} \mathrm{M}$ Frumovitz, ${ }^{2} \mathrm{~A}$ Zorrilla-Vaca, ${ }^{3} \mathrm{~B}$ Segarra Vidal, ${ }^{2} \mathrm{R}$ Dos Reis, ${ }^{2} \mathrm{M}$ Iniesta, ${ }^{2} \mathrm{P}$ Ramirez. ${ }^{1}$ Hospital Clínic de Barcelona, Barcelona, Spain; ${ }^{2}$ The University of Texas MD Anderson Cancer Center, Houston, USA; ${ }^{3}$ Hospital La Fe, Valencia, Spain

\subsection{6/ijgc-2021-ESG0.67}

Introduction/Background* Open approach has become the standard for many institutions when performing a radical hysterectomy for early cervical cancer. The objective of this study was to evaluate the length of stay after open radical hysterectomy before and after the implementation of Enhanced Recovery After Surgery (ERAS) pathway in a tertiary cancer center. Methodology This is a retrospective study of patients who underwent open radical hysterectomy for cervical cancer from January 2009 to December 2020. We distinguished two groups based on the time of ERAS implementation: group 1 (pre-ERAS) between January 2009 and October 2014 and group 2 (post-ERAS) between November 2014 and December 2020. We also defined two time periods according to the application of open radical hysterectomy as a standard of care. Univariate analysis was applied and $\mathrm{P}$ values were reported using chi-squared or Fisher's exact test.

Result(s)* A total of 81 patients were included; 29 patients in group 1 and 52 patients in group 2. There were no differences in terms of age (median of 42 years [35-53] in group 1 vs 41 years [35-49] in group $2 ; \mathrm{p}=0.47)$ and BMI $(26.1 \mathrm{~kg} /$

Abstract 771 Table 1 Postoperative outcomes group 1 (preERAS) vs group 2 (post-ERAS)

\begin{tabular}{llll}
\hline Outcome & $\begin{array}{l}\text { Gorup 1 (Pre-ERAS) } \\
2009-2014\end{array}$ & $\begin{array}{l}\text { Group 2 (Post-ERAS) } \\
2015-2020\end{array}$ & P value \\
& $\mathrm{N}=29$ & $\mathrm{~N}=52$ & \\
\hline Hospital stay & $4[3-4]$ & $3[2-3]$ & $<0.01$ \\
Blood transfusion (in-hospital), & $8(27.8 \%)$ & $8(15.4 \%)$ & 0.18 \\
Overall complication events & $13(44.8 \%)$ & $20(38.5 \%)$ & 0.57 \\
Clavien-Dindo & & & \\
None & $16(55.2 \%)$ & $32(61.5 \%)$ & 0.56 \\
I & $6(20.7 \%)$ & $9(17.3 \%)$ & 0.71 \\
II & $6(20.7 \%)$ & $13(25.0 \%)$ & 0.66 \\
III & $1(3.4 \%)$ & $3(5.7 \%)$ & 0.64 \\
IV & $1(3.4 \%)$ & $3(5.8 \%)$ & 0.64 \\
$<30$ days, $\mathrm{n}(\%)$ & & $9(17.3 \%)$ & \\
Readmission & $6(20.7 \%)$ & $1(1.9 \%)$ & 0.40 \\
$>30$ days, $\mathrm{n}(\%)$ & $3(10.3 \%)$ & & 0.05 \\
\hline Readmission & & & \\
\hline
\end{tabular}




\begin{tabular}{|c|c|c|c|}
\hline & $\begin{array}{l}\text { Pre-LACC (2009- } \\
2017) \\
(\mathrm{n}=35)\end{array}$ & $\begin{array}{l}\text { Post-LACC (2018- } \\
2020) \\
(n=46)\end{array}$ & $\begin{array}{l}P \\
\text { value }\end{array}$ \\
\hline Hospital stay & 3 [3-4] & $3[2-3]$ & $<0.01$ \\
\hline $\begin{array}{l}\text { Blood transfusion (in-hospital), } \\
\mathrm{n}\end{array}$ & $9(25.7 \%)$ & 7 (15.2\%) & 0.24 \\
\hline $\begin{array}{l}\text { Overall complication events } \\
\text { Clavien-Dindo }\end{array}$ & $14(40 \%)$ & $19(41.3 \%)$ & 0.91 \\
\hline None & $21(60 \%)$ & 27 (58.7\%) & 0.93 \\
\hline 1 & $7(20 \%)$ & $8(17.4 \%)$ & 0.76 \\
\hline$\|$ & $6(17.1 \%)$ & $13(28.3 \%)$ & 0.24 \\
\hline III & $1(2.8 \%)$ & $3(6.5 \%)$ & 0.45 \\
\hline $\begin{array}{l}\text { IV } \\
<30 \text { days, } \mathrm{n}(\%)\end{array}$ & $1(2.8 \%)$ & $3(6.5 \%)$ & 0.45 \\
\hline $\begin{array}{l}\text { Readmission } \\
>30 \text { days, n (\%) }\end{array}$ & $6(17.1 \%)$ & $9(19.6 \%)$ & 0.78 \\
\hline Readmission & $3(8.6 \%)$ & $1(2.2 \%)$ & 0.21 \\
\hline
\end{tabular}

$\mathrm{m}^{2}$ [24.6-29.7-53] in group 1 vs 27.1 in $\mathrm{kg} / \mathrm{m}^{2}[23.5-33.5]$ in group $2 ; \mathrm{p}=0.44)$. Patients in group 2 were discharged from the hospital earlier compared to group 1 (median 3 days [2-3] vs 4 days [3-5], $\mathrm{p}<0.01)$. There were no differences regarding overall complications (38.5\%, group 1 vs $44.8 \%$, group 2; $\mathrm{p}=0.57)$ and readmission rates within 30 days $(1.9 \%$, group 1 vs $10.3 \%$, group $2 ; \mathrm{p}=0.05)$. When analyzing the two periods in relation to change of institutional practice to exclusively open approach (November 2017-December 2020), the length of stay was also shorter (median 3 days [2-3] vs 3 days [3-4], $\mathrm{p}<0.01)$. Adherence to ERAS pathway remained stable to date with a median of 70\% [IQR 65-75\%].

Conclusion* Patients undergoing an open radical hysterectomy under an ERAS pathway have a decreased length of hospital stay without increasing overall complications nor readmissions rate.

\section{SURGERY IN CERVICAL CANCER OBSERVATIONAL PROSPECTIVE (SUCCOP), AN ESGO SURVEY: IS IT A PLACE FOR ANOTHER EUROPEAN PROSPECTIVE STUDY?}

1;2E Chacon*, 'N Manzour, 'F Boria, 'N Martín-Calvo, 'L Sánchez Lorenzo, 'D Vázquez, ${ }^{1} \mathrm{D}$ Salas, ${ }^{1} \mathrm{~T}$ Castellano, ${ }^{1} \mathrm{JA}$ Mínguez, ${ }^{1} \mathrm{JM}$ Aramendia, ${ }^{1} \mathrm{I}$ Brotons, ${ }^{1} \mathrm{~J}$ Vara, ${ }^{1}$ A Lopez-Picazo, 1J Espinos, 'M Cambeiro, 'M Gimeno, ${ }^{1} \mathrm{~F}$ Calvo, 'JL Alcazar, 'A Gonzalez-Martin, 1;3LM Chiva. 'clinica universidad de navarra; ${ }^{2}$ clinica universidad de navarra, gynecologic oncology, pamplona, Spain; ${ }^{3}$, Spain

\subsection{6/ijgc-2021-ESGO.68}

Introduction/Background" The study attempts to understand the impact of the different retrospective studies conducted by the SUCCOR group on the daily surgical practice among ESGO members.

We intend to propose a new observational prospective European study, the SUCCOP study. We aim to know if the implementation of protective maneuvers in minimally invasive surgery (MIS) improves the outcome of patients with early cervical cancer (ECC).

In this scenario, supported by the ESGO council, we have conducted a multinational survey to assess our ESGO members' perspectives from the ethical and investigational viewpoints on this new observational prospective study.

Would you consider ethically acceptable a new European Observational Prospective study (SUCCOP) to evaluate the surgical approach in early cervical cancer (IB1-IB2)?
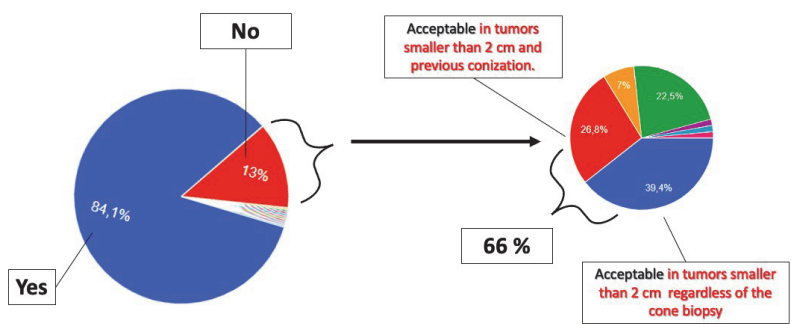

Abstract 779 Figure 1 